\title{
Correction to: Malignant Pleural Mesothelioma
}

\author{
Takashi Nakano and Takashi Kijima
}

\section{Correction to:}

Viral Immune Therapy and Other Virotherapies

for Advanced Mesothelioma: Are We Ready for

Clinical Trials of Viral Immune Therapy?

https://doi.org/10.1007/978-981-15-9158-7_25

In chapter 25, Table 1 - Current clinical trials of virontherapy for pleural mesothelioma has been included. 


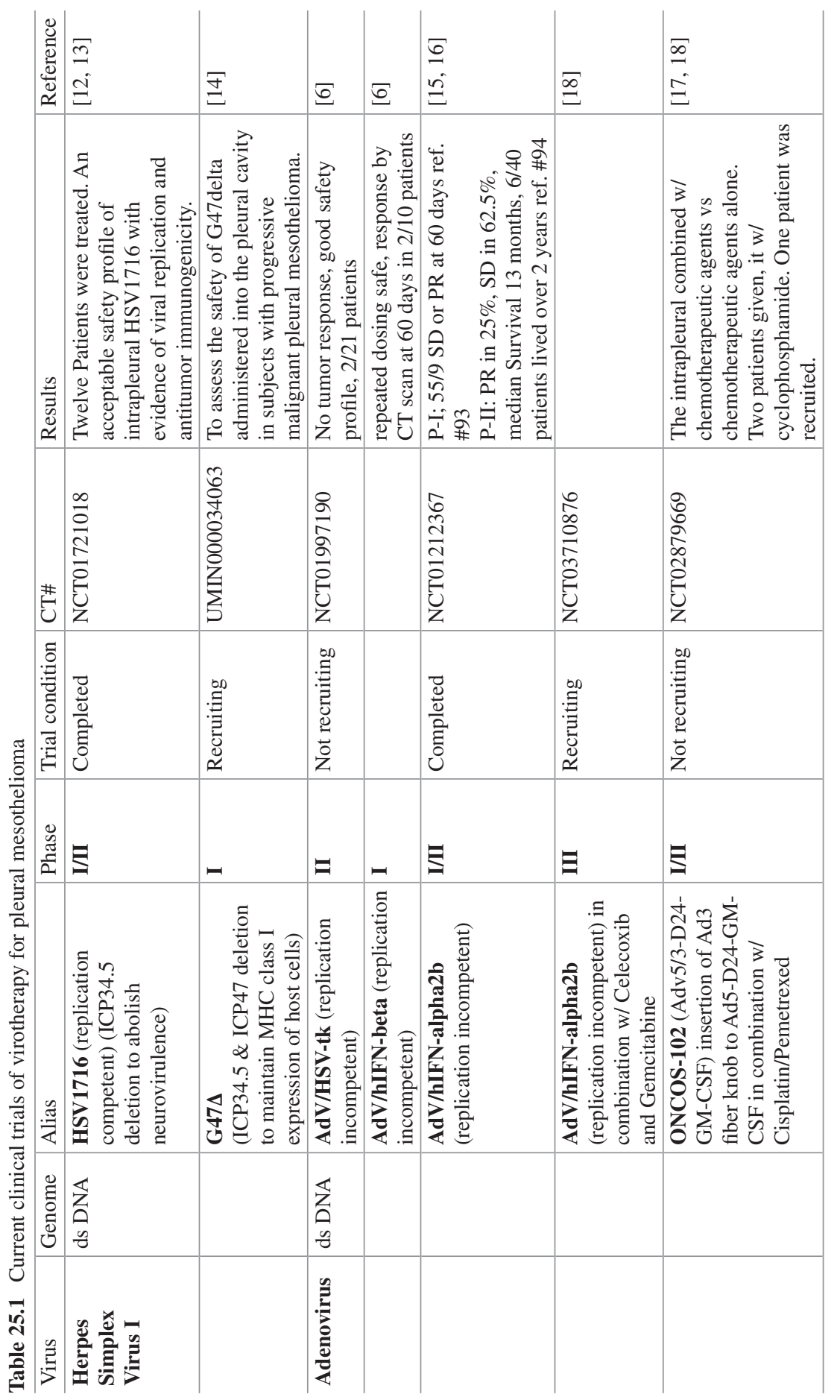




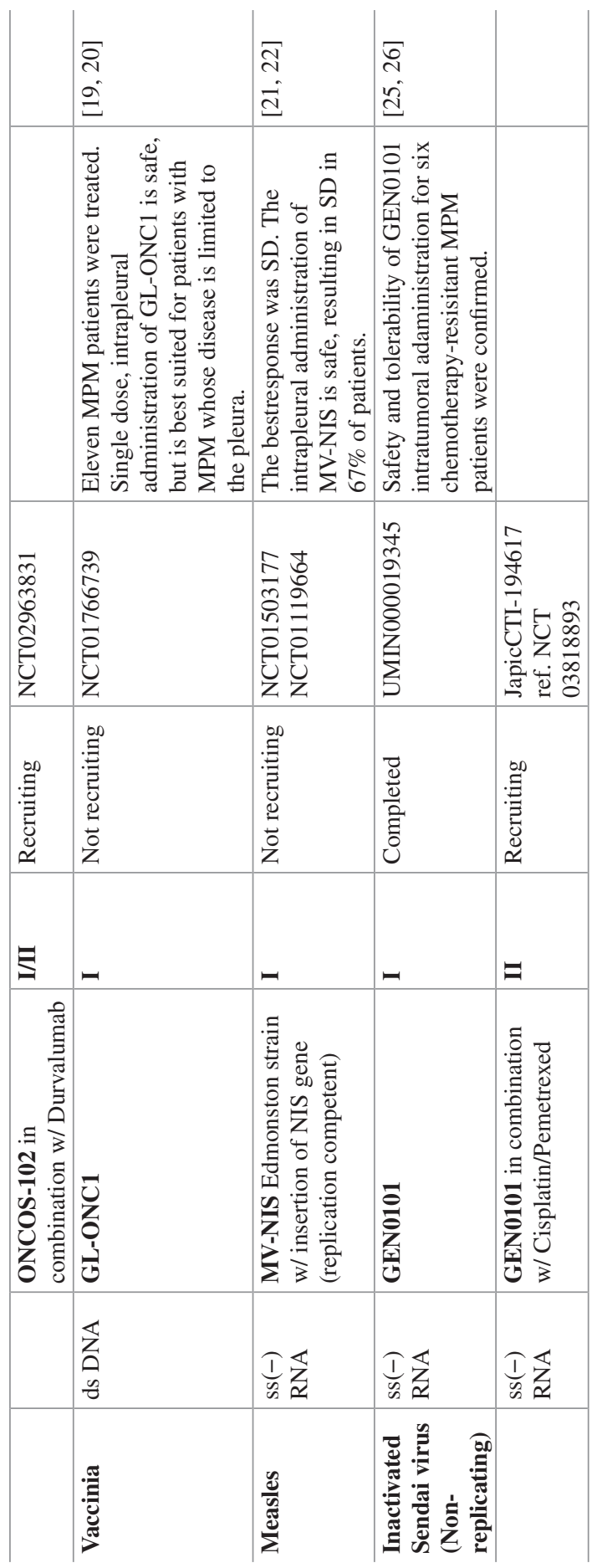

